\title{
Detection of antibiotic resistant Acinetobacter baumannii in various hospital environments: potential sources for transmission of Acinetobacter infections
}

\author{
Zahra Shamsizadeh', Mahnaz Nikaeen ${ }^{1 *}$, Bahram Nasr Esfahani², Seyed Hamed Mirhoseini', \\ Maryam Hatamzadeh ${ }^{1}$ and Akbar Hassanzadeh ${ }^{4}$
}

\begin{abstract}
Background: Antibiotic resistant Acinetobacter baumannii has emerged as one of the most problematic hospital acquired pathogens around the world. This study was designed to investigate the presence of antibiotic resistant $A$. baumannii in various hospital environments.

Methods: Air, water and inanimate surface samples were taken in different wards of four hospitals and analyzed for the presence of A. baumannii. Confirmed A. baumannii isolates were analyzed for antimicrobial susceptibility and also screened for the presence of three most common OXA- type carbapenemase-encoding genes.

Results: A. baumannii was detected in 11\% (7/64) of air samples with the highest recovery in intensive care units (ICUs). A. baumannii was also detected in 17\% (7/42) and 2\% (1/42) of surface and water samples, respectively. A total of $40 \mathrm{~A}$. baumannii isolates were recovered and analysis of antimicrobial susceptibility showed the highest resistance towards ceftazidime $(92.5 \%, 37 / 40) .85 \%(34 / 40)$ and $80 \%(32 / 40)$ of the isolates were also resistant to imipenem and gentamicin, respectively. Resistance genes analysis showed that $77.5 \%$ (31/40) strains contained OXA-23 and 5\% (2/40) strains contained OXA-24, but OXA-58 was not detected in any of the strains.

Conclusion: Detection of antibiotic resistant $A$. baumannii in various samples revealed that hospital environments could act as a potential source for transmission of $A$. baumannii infections especially in ICUs. These results emphasize the importance of early detection and implementation of control measures to prevent the spread of $A$. baumannii in hospital environments.
\end{abstract}

Keywords: Acinetobacter baumannii, Hospital, Antibiotic resistance, Air, Water, Surface

\section{Background}

Nosocomial infections have become increasingly a major health concern in many hospitals worldwide $[1,2]$. Nosocomial infections account for about 1.4 million infections every year [3]. Acinetobacter infections have frequently been reported as a major of nosocomial infections $[1,4,5]$.

Acinetobacter species, ubiquitous gram-negative coccobacilli, are widespread in nature, water and soil $[5,6]$.

\footnotetext{
* Correspondence: nikaeen@hlth.mui.ac.ir

${ }^{1}$ Department of Environmental Health Engineering, School of Health, Isfahan University of Medical Sciences, Hezar Jerib Avenue, Isfahan, Iran

Full list of author information is available at the end of the article
}

More than 20 species of Acinetobacter have been characterized but only few species including Acinetobacter baumannii, A. calcoaceticus and A. lwoffii play a significant role in nosocomial infections [6]. However, $A$. baumannii has the greatest clinical significance and identified as the causative agent of the majority of nosocomial infections especially in intensive care units (ICU) [6-8]. A. baumannii can cause a wide range of infections including bacteremia, meningitis, urinary tract, bloodstream or surgical wound infections and ventilator associated pneumonia $[5,6]$.

However, the emergence of antibiotics-resistant $A$. baumannii especially, multiresistant strains seriously 
challenges the treatment of these infections [9]. This is of special concern in developing countries, since antibiotic prescription rates and intake without prescription is markedly higher [9]. Antibiotic resistance causing increased morbidity, mortality, and economic impacts on health services [2]. Vulnerable groups of inpatients such as people with impaired host defenses are especially at high risk $[4,10]$. A. baumannii has the ability to survive for long periods and could easily spread in hospital environments [5]. These traits could define its propensity for causing extended outbreaks $[5,6]$.

A. baumannii is mainly transmitted by direct contact with infected persons or indirect contact with contaminated environments. However, airborne route also plays an important role in transmission of $A$. baumannii infections in hospitals $[2,11]$. Although, airborne transmission was considered as a route for acquisition of $A$. baumannii infections; there are very few studies in the field [11-14].

Prevention and control of hospital infections require knowledge about the sources and reservoirs of nosocomial infection agents [5]. In other words, identification of $A$. baumannii sources in hospital environments improves the knowledge of potential routes of $A$. baumannii transmission. Such information would also allow implementing more appropriate control policies against the spreading of $A$. baumannii infections.

Based on these premises, the present study was carried out in order to 1) determine the occurrence of A. baumannii in air, water and inanimate surface samples in different wards of four educational hospitals 2) evaluate the antibiotic resistance of isolated A. baumannii 3) Evaluate the frequency of three common OXA-type carbapenemaseencoding genes in isolated resistant bacteria 4) analyze the molecular diversity of $A$. baumannii isolates by repetitive extragenic palindromic sequence PCR (REP-PCR).

\section{Methods}

The study was carried out from April 2014 to April 2015 in four educational hospitals of Isfahan University of Medical Sciences, Isfahan, Iran. Air, water and surface samples were taken in four locations in each hospital including operating theatres $(\mathrm{OT})$, intensive care units (ICU), surgery wards (SW), and internal medicine wards (IM). Each hospital was visited 4 times and samples from various locations were taken on one single day after routine cleaning. A similar disinfection procedure was used for all hospitals. During the study period, patients, staffs, and patient attendants were present, but visitors were limited.

\section{Air samples}

A total of 64 air samples were collected at a calibrated flow rate of $10 \mathrm{l} / \mathrm{min}$ using an all-glass impinger (AGI), containing phosphate buffer solution. Air sampling was performed at a height of $1.5 \mathrm{~m}$ above the ground level to simulate the breathing zone and approximately $2400 \mathrm{~L}$ of air was collected using portable pump from each site. Temperature and relative humidity were recorded by use of a portable weather station (Kimo) throughout the sampling periods and were about $26 \pm 2.3{ }^{\circ} \mathrm{C}$ and $28 \% \pm$ $5.6 \%$, respectively.

\section{Surface samples}

A total of 42 surface samples were taken from patient beds in SW, IM and ICU of four hospitals. Surface samples were obtained by swabbing of beds surface with a saline solution moistened cotton swab. After sampling, swab was placed into a sterile tube containing $2 \mathrm{~mL}$ of $0.8 \%$ salt water and was transferred to the laboratory.

\section{Water samples}

Sampling of tap water was done in $250 \mathrm{ml}$ bottles containing thiosulfate from SW, IM and ICU of four hospitals.

All samples were transferred to the laboratory in an insulated box with cooling packs and processed immediately upon arrival in the laboratory.

\section{Detection of $A$. baumannii}

For detection of $A$. baumannii in air samples, aliquots of each impinger collection medium were plated onto blood agar and MacConkey agar after a vigorous shaking.

The saline suspension of surface samples was enriched overnight at $37{ }^{\circ} \mathrm{C}$ in brain heart infusion broth. Then, $0.3 \mathrm{ml}$ of liquid broth transferred to each of the blood agar and MacConkey agar.

Water samples were filtered by membrane filtration $(0.22 \mu \mathrm{m}, 47 \mathrm{~mm}$ in diameter, Millipore) and then filters were placed on MacConkey agar plates.

All MacConkey and blood agar plates were incubated at $37{ }^{\circ} \mathrm{C}$ for $72 \mathrm{~h}$. After incubation time non-repetitive colonies were isolated and confirmatory procedures by using conventional biochemical tests was performed [1]. Suspected colonies were also further verified using the Acinetobacter specific primer set Ac436F and Ac676r (Table 1), and $A$. baumannii identification was further confirmed by polymerase chain reaction (PCR) amplification of the inherent blaOXA-51 gene (Table 1) [12]. Confirmed A. baumannii isolates were analyzed for antimicrobial susceptibility and also screened for the presence of three most common OXA- type carbapenemase-encoding genes.

\section{Antimicrobial susceptibility testing}

Antimicrobial susceptibility analysis of the isolates was performed by disc diffusion method on Mueller-Hinton agar using ceftazidime $(30 \mu \mathrm{g})$, imipenem $(10 \mu \mathrm{g})$ and gentamicin $(10 \mu \mathrm{g})$ according to the recommendations 
Table 1 Primers used in the study

\begin{tabular}{|c|c|c|c|c|}
\hline Primers & Sequence $\left(5^{\prime} \rightarrow 3^{\prime}\right)$ & Amplified fragment (bp) & Annealing temperature & Reference \\
\hline $\begin{array}{l}\text { Ac436 } \\
\text { Ac676 }\end{array}$ & $\begin{array}{l}\text { TTAAAGCGAGGAGGAGG } \\
\text { ATTCTACCATCCTCTCCC }\end{array}$ & 240 & 56 & [30] \\
\hline OXA-51 & $\begin{array}{l}\text { F: TAATGCTTTGATCGGCCTTG } \\
\text { R: TGGATTGCACTTCATCTTGG }\end{array}$ & 353 & 57 & [31] \\
\hline OXA-23 & $\begin{array}{l}\text { F: GATCGGATTGGAGAACCAGA } \\
\text { R: ATTTCTGACCGCATTTCCAT }\end{array}$ & 501 & 54 & [31] \\
\hline OXA-24 & $\begin{array}{l}\text { F: GGTTAGTTGGCCCCCTTAAA } \\
\text { R: AGTTGAGCGAAAAGGGGATT }\end{array}$ & 246 & 54 & [31] \\
\hline OXA-58 & $\begin{array}{l}\text { F: AAGTATTGGGGCTTGTGCTG } \\
\text { R: CCCCTCTGCGCTCTACATAC }\end{array}$ & 599 & 54 & [31] \\
\hline REP & $\begin{array}{l}\text { REP1: IIIGCGCCGICATCAGGC } \\
\text { REP 2: ACGTCTTATCAGGCCTAC }\end{array}$ & - & 43 & [16] \\
\hline
\end{tabular}

of the Clinical and Laboratory Standards Institute (CLSI) [15]. For quality control, standard strain of E. coli (ATCC 25922) was used.

\section{Detection of OXA-type carbapenemase-encoding genes}

A. baumannii isolates were screened for 3 common OXA-type carbapenemase-encoding genes including blaOXA-23, blaOXA-58 and blaOXA-24 by PCR amplification with specific three sets of primers (Table 1).

\section{PCR amplification}

A loopful of each isolate was put into $100 \mu \mathrm{l}$ of deionized water. Then the suspension was vortexed and DNA was extracted by boiling for $15 \mathrm{~min}$ and centrifugation at $13,000 \mathrm{rpm}$ for $10 \mathrm{~min}$. Supernatant was used for PCR amplification. All PCR reactions were performed in a final volume of $25 \mu \mathrm{l}$ containing $2.5 \mu \mathrm{l}$ of $10 \mathrm{x}$ PCR buffer $\left(2 \mathrm{mM} \mathrm{MgCl}_{2}\right), 0.2 \mu \mathrm{M}$ of each primer, $0.2 \mathrm{mM}$ of each of the dNTPs, 2 units of Taq DNA polymerase, and $2 \mu \mathrm{l}$ template DNA. The PCR cycling conditions were as follows: initial denaturation at $94{ }^{\circ} \mathrm{C}$ for $5 \mathrm{~min}$, followed by 35 cycles of $45 \mathrm{~s}$ at $94{ }^{\circ} \mathrm{C}$, primer annealing at varied temperatures (Table 1) for $45 \mathrm{~s}$, primer extension at $72{ }^{\circ} \mathrm{C}$ for $45 \mathrm{~s}$, and final extension at $72{ }^{\circ} \mathrm{C}$ for $10 \mathrm{~min}$. All PCR assays included positive (A. baumannii, ATCC 19606) and negative controls. PCR products were analyzed by electrophoresis using $1.5 \%(\mathrm{w} / \mathrm{v})$ agarose gel. Gels were analyzed using an ultraviolet (UV) transilluminator (UV Tech, France).

REP- PCR

Genotype comparison was carried out for evaluating clonality of the isolates. The primers REP1 and REP2 (Table 1) were used and PCR amplification of the isolates was performed as described previously [16].

\section{Results}

Detection of $A$. baumannii in air, surface and water samples

Concentration of airborne bacteria in the hospitals ranged from 1 to $2355 \mathrm{CFU} / \mathrm{m}^{3}$. A. baumannii was detected in a concentration from 8 to $56 \mathrm{CFU} / \mathrm{m}^{3}$ in air samples. The mean concentrations of detected airborne bacteria and A. baumannii in each hospital ward are presented in Table 2.

A. baumannii was detected in $11 \%$ (7/64) of air samples. Percent of air positive samples for A. baumannii in various wards of four hospitals is presented in Table 3. As the data shows A. baumannii was not detected in air samples of hospital D as well as in air samples at any of the operating theatres of hospitals.

Table 3 also shows the percent of surface and water samples which $A$. baumannii was detected. A. baumannii was detected in $17 \%(7 / 42)$ and $2 \%(1 / 42)$ surface and water samples, respectively. Data of Table 3 shows that $A$. baumannii was detected with the highest frequency in air and surface samples of ICUs.

A total of $40 \mathrm{~A}$. baumannii isolates were recovered from positive samples including air samples 30\% (12/ $40)$, patient beds $67.5 \%(27 / 40)$ and water samples $2.5 \%(1 / 40)$.

Table 2 Mean concentration $\left(\mathrm{CFU} / \mathrm{m}^{3}\right)$ of airborne bacteria (A. baumannii) $^{\mathrm{a}}$ in different hospital wards

\begin{tabular}{|c|c|c|c|c|}
\hline & Hospital A & Hospital B & Hospital C & Hospital D \\
\hline \multicolumn{5}{|c|}{ Hospital ward } \\
\hline ICU & $43(8)$ & 194(14) & $23(56)$ & 61 (ND) \\
\hline OT & 617(ND) & 16.43 (ND) & $28(N D)$ & $17(\mathrm{ND})$ \\
\hline SW & $61(14)$ & 379.63 (ND) & $50(\mathrm{ND})$ & 352 (ND) \\
\hline IM & $32(14)$ & $104(17)$ & 26 (ND) & 19 (ND) \\
\hline
\end{tabular}

ICU intensive care unit, OT operating theatre, SW surgery ward, IM internal medicine ward, ND not detected

${ }^{\mathrm{a} C}$ Concentration of $A$. baumannii in positive samples 
Table 3 Percentage (No. of positive samples/total samples in each ward) of A. baumannii positive environmental samples in different hospital wards

\begin{tabular}{|c|c|c|c|c|c|c|c|c|c|c|c|c|c|c|c|c|c|}
\hline \multirow[b]{2}{*}{ Location } & \multicolumn{4}{|l|}{ Hospital A } & \multicolumn{4}{|l|}{ Hospital B } & \multicolumn{4}{|l|}{ Hospital C } & \multicolumn{4}{|c|}{ Hospital D } & \multirow[b]{2}{*}{ Total } \\
\hline & $\mathrm{ICU}$ & OT & SW & IM & ICU & OT & SW & $\mathrm{IM}$ & ICU & OT & SW & $\mathrm{IM}$ & ICU & OT & SW & $\mathrm{IM}$ & \\
\hline Air sample & $25 \%(1 / 4)$ & ND & $25 \%(1 / 4)$ & $25 \%(1 / 4)$ & $25 \%(1 / 4)$ & ND & ND & $50 \%(2 / 4)$ & $25 \%(1 / 4)$ & ND & ND & $N D$ & ND & ND & ND & ND & $11 \%(7 / 64)$ \\
\hline $\begin{array}{l}\text { Surface } \\
\text { sample }\end{array}$ & $67 \%(2 / 3)$ & - & $33 \%(1 / 3)$ & ND & $100 \%(3 / 3)$ & - & ND & ND & ND & - & ND & ND & ND & - & ND & $25 \%(1 / 4)$ & $17 \%(7 / 42)$ \\
\hline $\begin{array}{l}\text { Water } \\
\text { sample }\end{array}$ & ND & - & ND & ND & ND & - & $25 \%(1 / 4)$ & ND & ND & - & ND & ND & ND & - & ND & ND & $2 \%(1 / 42)$ \\
\hline
\end{tabular}

ICU intensive care unit, OT operating theatre, SW surgery ward, IM internal medicine ward, ND not detected

\section{Antimicrobial susceptibility of $A$. baumannii isolates}

Analysis of antimicrobial susceptibility in this study showed that $100 \%(12 / 12)$ of A. baumannii isolates from air samples were resistant to ceftazidime, imipenem and gentamicin. In other words, all air isolates were multidrug resistant. A. baumannii isolated from water sample was also resistant to ceftazidime and gentamicin but not imipenem. However, 70\% (19/27) of the isolates from surface samples were resistant to gentamicin and $81 \%$ $(22 / 27)$ and $89 \%(24 / 27)$ were resistant to imipenem and ceftazidime, respectively. Overall, ceftazidime resistant A. baumannii was the most frequently detected isolates $(92.5 \%, 37 / 40)$ followed by imipeneme resistant (85\%, $34 / 40)$ isolates.

\section{OXA-type carbapenemase-encoding genes in $A$.}

\section{baumannii isolates}

Figure 1 shows the frequency of carbapenemase-encoding genes in A. baumannii isolates. 77.5\% (31/40) strains contained OXA-23, 5\% (2/40) strains contained OXA-24 and OXA-58 was not detected in any of the strains.

\section{REP-PCR}

Analysis of REP-PCR showed 10 different patterns. Figure 2 shows the REP-PCR pattern of some isolates.

\section{Discussion}

Over the past two decades, antibiotic resistant $A$. baumannii has emerged as one of the most problematic hospital acquired pathogens $[4,17,18]$.

The results of this study showed the presence of $A$. baumannii in various hospital environments including air, inanimate surface and water. A. baumannii was isolated from $11 \%(7 / 64)$ of air samples. Other investigations on hospital air also reported the presence of Acinetobacter species and A. baumannii [12-14, 19]. In the study of Gao et al. [12] on air samples from burn wards of a general hospital in China, 16 samples were found positive for A. baumannii. However, the majority of air samples were negative. Munoz-Price et al. [14] also reported the presence of $A$. baumannii in 22.6\% (12/53) of air samples in a trauma ICU. Our results showed that the highest detection was related to ICUs. It has been demonstrated that A. baumannii is responsible for a high percentage of ventilator-associated pneumonia which occurs predominantly in ICU patients with mechanical ventilation $[1,4]$. There is some evidence that hospital air plays a significant role in the transmission of A. baumannii infections [2, 11]. Bernards et al. [20] reported the airborne route of $A$. baumannii outbreaks in two Dutch hospitals. A. baumannii aerosols could be released from various sources including respiratory

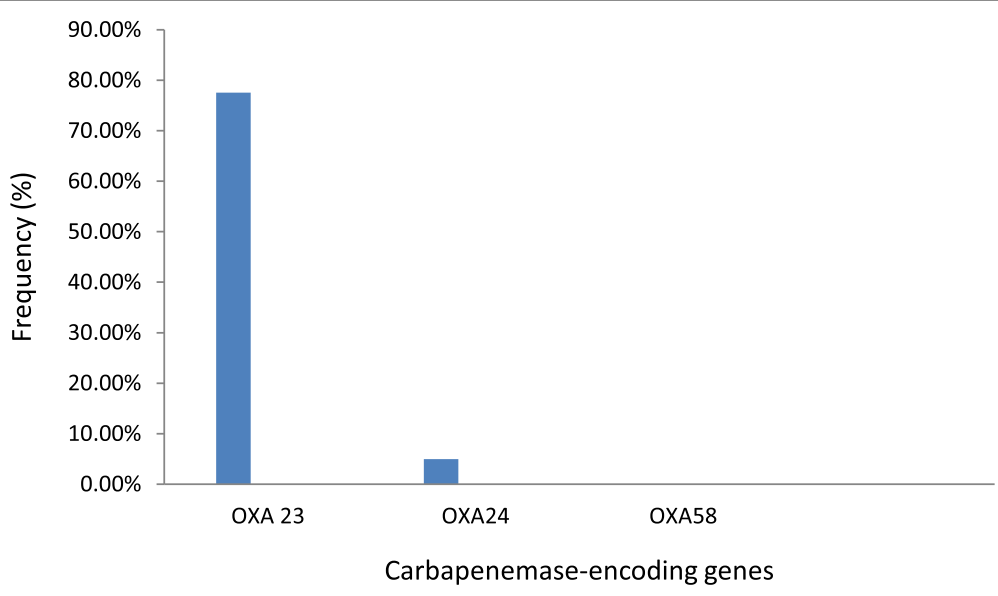

Fig. 1 Frequency of detection of different groups of carbapenemase-encoding genes in A. baumannii isolates 


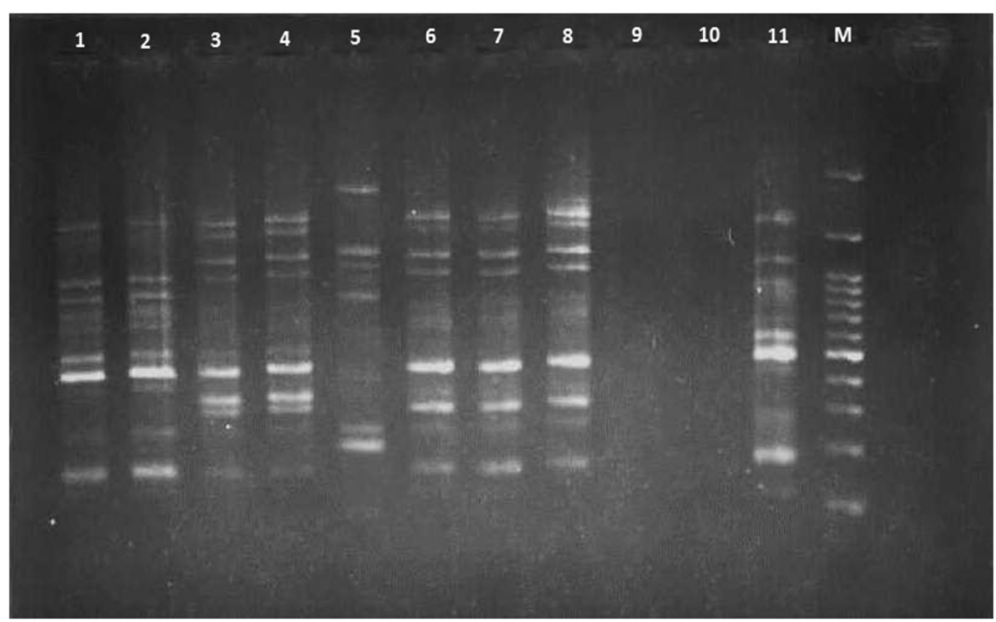

Fig. 2 REP-PCR pattern of some A. baumannii isolates. 1-8: A. baumannii isolates, 9-10: negative control, 11: positive control (A. baumannii, ATC(19606), M: 100 bp marker

droplets produced by patients, ventilation and air conditioning systems and also ward activities such as those generated by bed making and mechanical floor cleaning $[2,13,21]$.

Analysis of water samples revealed the presence of $A$. baumannii in one sample of SW. Hospital water systems were known to be colonized by some nosocomial pathogens such as Legionella pneumophila and Pseudomonas aeruginosa and could act as a potential source for aerosolized nosocomial pathogens $[22,23]$.

It is also possible that airborne bacteria deposited on inanimate surfaces [2]. Our results showed that 17\% (7/42) of patient beds were contaminated with A. baumannii and ICUs had the highest rate of contamination. Study of Custovic et al. [4] showed that $17.7 \%$ (31/175) swabs were taken from hospital surfaces, medical equipment and hands of medical staffs were positive for some nosocomial pathogens with the highest isolation rate of $A$. baumannii (51.6\%).

Detection of A. baumannii in air, water and inanimate surface samples revealed that hospital environments could act as a potential route for transmission of $A$. baumannii infections especially in ICUs. Several studies demonstrated the relation between $A$. baumannii outbreaks and environmental sources such as patient beds, air conditioners and ventilation equipment. In the study of Aygun et al. [24] A. baumannii was isolated from $39.3 \%$ (22/59) environmental samples obtained by swabbing in ICU. They concluded that environmental contamination has an important reservoir role in outbreaks of A. baumannii in ICUs. Results of Tena et al. [25] showed that all five clinical isolates and one environmental isolate belonged to a single clone. Based on the clonal relationship of the isolates by pulsed-field gel electrophoresis (PFGE), they concluded that the infection source has probably been the hands of the healthcare workers [25]. Similarly, Cicek et al. [7] suggested that all the patients and environmental isolates were derived from a common source.

A. baumannii isolates showed the highest resistance towards ceftazidime $(92.5 \%, 37 / 40)$. It has been reported that a high portion of clinically isolated $A$. baumannii are resistant to cephalosporins such as ceftazidime [18]. Our results also showed that a high percentage of $A$. baumannii isolates were resistant to imipenem $(85 \%, 34 / 40)$ and all air isolates were multidrug resistant [6]. In consistent with our results, Gao et al. [12] reported that $93.75 \%$ (15/16) A. baumannii isolates from air samples were resistant to imipenem. Carbapenems resistant strains of $A$. baumannii have been associated with considerable mortality and hospital costs $[26,27]$. Crude mortality of infections caused by these strains ranges from 16 to $76 \%$ [27]. High resistance rate of A. baumannii to carbapenems has been frequently observed in clinical isolates [4, 28]. However, some European studies reported much lower resistance to carbapenems [28]. Antimicrobial susceptibility analysis revealed the lowest resistance towards gentamicin.

However, 67.5\% (27/40) of A. baumannii isolates were multidrug resistant [6]. Multidrug resistant A. baumannii, in particular carbapenem resistant has a propensity to cause hospital infections [18].

The results showed that OXA-23 was the most frequent gene $(77.5 \%, 31 / 40)$ detected in A. baumannii isolates. The OXA-23 gene was detected in all of air isolates except one isolate. This result suggests that the OXA-23 was the main cause of the resistance of $A$. baumannii isolates from air, water and surface samples in our hospitals. Other investigations also reported OXA23 group as the most prevalent carbapenemase-encoding gene [18]. Gao et al. [12] also found 15/16 strains from air samples were positive for OXA-23 gene. Pajand et al. 
[10] reported a high prevalence of blaOXA-23 (68\%) in carbapenems resistant $A$. baumannii isolates. However, we could not detect any OXA-58 gene and OXA-24 was found only in two isolates of air samples. In the study of Gao et al. [12], OXA-24 and -58 were not detected in any air isolates. Tena et al. [25] detected OXA-24 carbapenemase in all five isolates from patients and one isolate from surface of a serum container. Conversely, studies in Italy reported the frequent isolation of OXA58 producing $A$. baumannii [29].

Genotype comparison of the 40 isolates showed 10 distinct patterns. REP-PCR results analysis showed no high similarity between air, surface and water isolates from various wards. A unique REP-PCR profile was only observed in isolates from a surface sample of SW in hospital $\mathrm{A}$ and air sample isolate of ICU in hospital C. These results demonstrated that $A$. baumannii isolates were derived from various sources in hospital environments.

\section{Conclusion}

The results of this study showed the presence of multidrug resistant $A$. baumannii in various hospital environments including air, water and surface. Based on the results of PCR analysis of carbapenemase-encoding genes, OXA-23 was the main cause of the antibiotic resistance of A. baumannii isolates. Therefore, early detection and implementation of appropriate control measures are crucial in preventing of transmission of A. baumannii infections through hospital environments, especially in ICUs.

\section{Abbreviations \\ A. baumannii: Acinetobacter baumannii; AGl: All-glass impinge; CFU: Colony forming unit; ICU: Intensive care unit; IM: Internal medicine; OT: Operating theatre; PCR: Polymerase chain reaction; REP-PCR: Repetitive extragenic palindromic sequences PCR; SW: Surgery ward}

\section{Acknowledgements}

This research was conducted with funding from the vice chancellery for research of Isfahan University of Medical Sciences (Research Project \#393264) as a MS dissertation thesis.

\section{Funding}

This research was conducted with funding from the vice chancellery for research of Isfahan University of Medical Sciences only for collection of samples and analyses.

\section{Availability of data and materials}

The datasets used and/or analyzed during the current study available from the corresponding author on reasonable request.

\section{Authors' contributions}

ZS participated in the design of the study, performed samples collection and analyses and helped to draft the manuscript. MN designed and supervised the study and drafted the manuscript. BNE participated in the design of the study. SHM participated in the samples collection and analyses. MH participated in the samples analyses. AH participated in the design of the study and performed the statistical analysis. All authors read and approved the final manuscript.

\section{Competing interests}

The authors declare that they have no competing interests.
Consent for publication

Not applicable.

Ethics approval and consent to participate

Not applicable.

\section{Publisher's Note}

Springer Nature remains neutral with regard to jurisdictional claims in published maps and institutional affiliations.

\section{Author details}

${ }^{1}$ Department of Environmental Health Engineering, School of Health, Isfahan University of Medical Sciences, Hezar Jerib Avenue, Isfahan, Iran. ${ }^{2}$ Department of Microbiology, School of Medicine, Isfahan University of Medical Sciences, Isfahan, Iran. ${ }^{3}$ Department of Environmental Health Engineering, School of Health, Arak University of Medical Sciences, Arak, Iran. ${ }^{4}$ Department of Statistics and Epidemiology, School of Health, Isfahan University of Medical Sciences, Isfahan, Iran.

Received: 28 December 2016 Accepted: 20 April 2017

Published online: 08 May 2017

\section{References}

1. Kilic A, Li H, Mellmann A, et al. Acinetobacter septicus sp. nov. association with a nosocomial outbreak of bacteremia in a neonatal intensive care unit. J Clin Microbiol. 2008;46:902-8.

2. Beggs $C$. The airborne transmission of infection in hospital buildings: fact or fiction? Indoor Built Environ. 2003;12:9-18.

3. Pittet $D$, Donaldson L. Clean Care is Safer Care: a worldwide priority. Lancet. 2005;366:1246-7.

4. Custovic A, Smajlovic J, Tihic N, Hadzic S, Ahmetagic S, Hadzagic H. Epidemiological Monitoring of Nosocomial Infections Caused by Acinetobacter Baumannii. Med Arh. 2014;68:402-6.

5. Fournier PE, Richet $\mathrm{H}$, Weinstein RA. The epidemiology and control of Acinetobacter baumannii in health care facilities. Clin Infect Dis. 2006:42:692-9.

6. Bergogne-Berezin E, Towner K. Acinetobacter spp. as nosocomial pathogens: microbiological, clinical, and epidemiological features. Clin Microbiol Rev. 1996;9:148-65.

7. Cicek AC, Karagoz A, Koksal E, et al. A Single Clone Acinetobacter baumannii Outbreak in a State Hospital in Turkey. Jpn J Infect Dis. 2013;66:245-8.

8. Benedetta L, Annalisa P, Ida L, et al. Molecular findings and antibioticresistance in an outbreak of Acinetobacter baumannii in an intensive care unit. Ann Ist Super Sanita. 2007;43(1):83-8.

9. Levy SB, Marshall B. Antibacterial resistance worldwide: causes, challenges and responses. Nat Med. 2004;10:S122-9.

10. Pajand O, Rezaee MA, Nahaei MR, Mahdian R, Aghazadeh M, Soroush MH, et al. Study of the carbapenem resistance mechanisms in clinical isolates of Acinetobacter baumannii: Comparison of burn and non-burn strains. Burns. 2013;39:1414-9.

11. Akalin H, Özakin C, Gedikoğlu S. Epidemiology of Acinetobacter baumannii in a university hospital in Turkey. Infect Control. 2006;27:404-8.

12. Gao J, Zhao X, Bao Y, et al. Antibiotic resistance and OXA-type carbapenemases-encoding genes in airborne Acinetobacter baumannii isolated from burn wards. Burns. 2014;40:295-9.

13. Wang S, Sheng W, Chang Y, et al. Healthcare-associated outbreak due to pan-drug resistant Acinetobacter baumannii in a surgical intensive care unit. J Hosp Infect. 2003:53:97-102.

14. Munoz-Price LS, Fajardo-Aquino Y, Arheart KL, et al. Aerosolization of Acinetobacter baumannii in a trauma ICU. Crit Care Med. 2013;41:1915-8.

15. CLSI. Performance Standards for Antimicribial Sucseptibility Testing. TwentySecond Informational Supplement. Wayne: CLSI document M100-S22; 2012.

16. Bou G, Cervero G, Dominguez M, Quereda C, Martínez-Beltrán J. PCRbased DNA fingerprinting (REP-PCR, AP-PCR) and pulsed-field gel electrophoresis characterization of a nosocomial outbreak caused by imipenem-and meropenem-resistant Acinetobacter baumannii. Clin Microbiol Infect. 2000;6:635-43.

17. Weinstein RA, Hota B. Contamination, disinfection, and cross-colonization: are hospital surfaces reservoirs for nosocomial infection? Clin Infect Dis. 2004;39:1182-9. 
18. Murray G, Peleg A, editors. Acinetobacter baumannii: Evolution of Antimicrobial Resistance-Treatment Options. Seminars in respiratory and critical care medicine. 2015.

19. Sarıca S, Asan A, Otkun MT, Ture M. Monitoring indoor airborne fungi and bacteria in the different areas of Trakya University Hospital, Edirne, Turkey. Indoor Built Environ. 2002;11:285-92.

20. Bernards AT, Frénay HM, Lim BT, Hendriks WD, Dijkshoorn L, van Boven CP. Methicillin-resistant Staphylococcus aureus and Acinetobacter baumannii: an unexpected difference in epidemiologic behavior. Am J Infect Control. 1998;26:544-51.

21. Tang J, Li Y, Eames I, Chan P, Ridgway G. Factors involved in the aerosol transmission of infection and control of ventilation in healthcare premises. J Hosp Infect. 2006;64:100-14.

22. Asghari FB, Nikaeen M, Hatamzadeh M, Hassanzadeh A. Surveillance of Legionella species in hospital water systems: the significance of detection method for environmental surveillance data. J Water Health. 2013;11:713-9.

23. Asghari FB, Nikaeen M, Mirhendi H. Rapid monitoring of Pseudomonas aeruginosa in hospital water systems: a key priority in prevention of nosocomial infection. FEMS Microbiol Lett. 2013;343:77-81.

24. Aygün $\mathrm{G}$, Demirkiran $\mathrm{O}$, Utku $\mathrm{T}$, et al. Environmental contamination during a carbapenem-resistant Acinetobacter baumannii outbreak in an intensive care unit. J Hosp Infect. 2002;52:259-62.

25. Tena D, Martínez NM, Oteo J, et al. Outbreak of multiresistant OXA-24-and OXA-51-producing Acinetobacter baumannii in an internal medicine ward. Jpn J Infect Dis. 2013;66:323-6.

26. Lautenbach E, Synnestvedt M, Weiner MG, et al. Epidemiology and impact of imipenem resistance in Acinetobacter baumannii. Infect Control. 2009:30:1186-92.

27. Lemos E, de la Hoz F, Einarson T, et al. Carbapenem resistance and mortality in patients with Acinetobacter baumannii infection: systematic review and meta-analysis. Clin Microbiol Infect. 2014;20:416-23.

28. Cai Y, Chai D, Wang R, Liang B, Bai N. Colistin resistance of Acinetobacter baumannii: clinical reports, mechanisms and antimicrobial strategies. J Antimicrob Chemother. 2012;67:1607-15.

29. D'Arezzo S, Principe L, Capone A, Petrosillo N, Petrucca A, Visca P. Changing carbapenemase gene pattern in an epidemic multidrug-resistant Acinetobacter baumannii lineage causing multiple outbreaks in central Italy. J Antimicrob Chemother. 2011;66:54-61.

30. Vanbroekhoven K, Ryngaert A, Wattiau P, De Mot R, Springael D. Acinetobacter diversity in environmental samples assessed by 165 rRNA gene PCR-DGGE fingerprinting. FEMS Microbiol Ecol. 2004;50:37-50

31. Woodford N, Ellington MJ, Coelho JM, Turton JF, Ward ME, Brown S, et al. Multiplex PCR for genes encoding prevalent OXA carbapenemases in Acinetobacter spp. Int J Antimicrob Agents. 2006;27:351-3.

\section{Submit your next manuscript to BioMed Central and we will help you at every step:}

- We accept pre-submission inquiries

- Our selector tool helps you to find the most relevant journal

- We provide round the clock customer support

- Convenient online submission

- Thorough peer review

- Inclusion in PubMed and all major indexing services

- Maximum visibility for your research

Submit your manuscript at www.biomedcentral.com/submit

) Biomed Central 